\title{
Changing economic systems and institutional dimensions of the Triple Helix model
}

\author{
Farshad Momeni ${ }^{1}$, Ali Arab Mazar Yazdi ${ }^{1}$ and Seyed Mohammad Sajjad Najafi ${ }^{*}$
}

\author{
* Correspondence: sajad.najafi.90@ \\ gmail.com \\ ${ }^{2}$ Master graduate of Allameh \\ Tabataba'i University of Tehran, \\ Tehran, Iran \\ Full list of author information is \\ available at the end of the article
}

\begin{abstract}
In recent decades, many efforts have been put into understanding and determining key variables and factors affecting knowledge-based economy. Triple Helix model is a model with relative success in this regard; however, there is still a long way to go until it can provide policy makers and researchers with an inclusive and deep insight. Researchers of the current study strived to distinguish one of the main theoretical shortcomings of the model, i.e., considering reward systems reformation firmly fixed in the institutional framework of society, while introducing an overview of the Triple Helix model and its underlying logic using a descriptive-analytical method based upon theoretical framework of new institutionalism. This paper aims to highlight that, in the developing countries' path toward a knowledge-based economy, reward systems reformation plays a key role and it is worth to be considered in models of determining the knowledge-based economy, the Triple Helix model, in particular.

Keywords: Innovation, Knowledge-based economy, Triple Helix model, Reward system

JEL: 010,043, B52
\end{abstract}

\section{Introduction}

In the past few centuries, fundamental transformations occurred in economic theories and practices. Transition from agricultural economy to industrial economy may be the most significant one. A transformation that not only changed the production function, the structure of property rights, and the reward mechanism of economic structure, but also completely changed all aspects of collective life of humans. It transformed rural life to urban life, changed the political systems, and patterns of consumption. It also led to the emergence of concepts such as equal citizenship rights and gender equality, etc. These were signs of a huge transformation which is properly known as the Industrial Revolution.

However, this socioeconomic phenomena provided the ground for a new evolution, far broader and more extensive. "Since the early 1990s, due to rapid progress of knowledge and economic globalization, models of production, distribution and consumption of economic goods have undergone profound changes and early signs of formation of a new economic system, with knowledge as its most important production factor,

(C) The Author(s). 2019 Open Access This article is distributed under the terms of the Creative Commons Attribution 4.0 International License (http://creativecommons.org/licenses/by/4.0/), which permits unrestricted use, distribution, and reproduction in any medium, provided you give appropriate credit to the original author(s) and the source, provide a link to the Creative Commons license, and indicate if changes were made. 
emerged" (Momeni et al. 2012, p. 1). Focus on material capitals in economic processes was quickly replaced by importance of knowledge.

Understanding the significance of the new economic structure is important since, aligned with changing rules of economic performance, there will be significant and wide spread changes in international economic, social, and political advantages. These changes spread into policy-making priorities of the countries in different regions. Pattern of knowledge-based economy provide countries with unique development opportunities; for instance, the possibility of benefiting from sustained high economic growth rate.

The Triple Helix model is one the patterns that has determined the most important variables affecting knowledge-based economy and the relationship between these variables so as to understand the knowledge-based economy. "In Triple Helix (TH) innovation model, the academia (colleges, universities), government and industry constitute the three helices which collaborate with each other in order to create or discover new knowledge, technology, products and services" (Report of Quadruple Helix Research For the CLIQ Project 2010, p. 14).

Ever since the evolutionary economists proposed the concept of "knowledge-based economy" (Lundvall and Foray 1996; Abramowitz and David 1996), the question of measuring this new type of economic cooperation has been raised (Carter 1996; OECD 1996). The Triple Helix model is formed based on extended theories of linear innovation which focused on mutual interaction between academia and industry and understanding the changing nature of innovation in modern economy. Changes in knowledge result in changes in production functions, market values, and aspirations. New techniques, new ways of doing the same things, and doing new things-all invoke harmful and beneficial effects to which society has not been accustomed.

Studies that worked on this model assumes that promoting interactions among the three dynamic sub-dynamics, i.e., university, industry, and government (as the main institutions involved in the knowledge market), can result in institutional synergy as well as growth of knowledge-based innovation by ensuring intellectual property rights and reducing uncertainty in the knowledge market. Indeed, the model considers the synergy, a concept for intellectual property rights in scientific innovation, as an indicator for achieving knowledge-based economy.

This study, using theoretical literature, tries to add another factor that contributes to the realization of a knowledge base Economy, reform of the reward structure. We state that, in this model, no decent attention has been paid to the reward structure and too much attention has been focused on Intellectual property. In this regards, the paper tried to explore one of the shortcomings of the Triple Helix Model in analyzing and explaining the situation of developing countries in terms of moving towards knowledge-based economy.

\section{Literature review}

Despite undeniable potentials and capacities of this model in analyzing the structure of knowledge-based economy, there is still a long way to reach the desired point. In order to overcome the shortcomings of the Triple Helix model and in an attempt to better understand its potentials, several studies proposed a revision for it. Including: 
1. Meyer et al. (2013) conducted a research on how the Triple Helix indicators were developed. By examining the body of literature over the past 15 years, they observed a variety of approaches to capture, depict, and measure the dynamics of the Triple Helix relations. In doing so, the common bibliographic method, that reviews articles based on common references, and bibliographic citation, that indicates articles reference to each other, are applied in combination with content analysis to develop a better understanding of the literature. They identified several clusters of studies as follows: (1) strands of activities that are to measure flows overlap and dynamics of the trilateral relations, (2) the second strand of activities refer to the triple helix framework but with a focus on measuring the results of academic entrepreneurship as well as relevant issue-based indicators, and (3) strands of activities that focus on indicators of the relationship between science and technology, in particular and can be summed up in two broad research stream management; the essence of "modern technology" and the nature of "modern institutionalism."

2. Cai's (2013) study strongly emphasizes on comparing ideal institutional logics grounded on the Triple Helix model with institutional logics prevailing within one country with innovative policies related to the Triple Helix model so as to make a deeper understanding of it. In an attempt to raise the underlying sensitivity, he measures the Triple Helix model in two ways. Accordingly, he identified common practices in Western societies in which the Triple Helix model is grounded and traced their underlying institutional logic. In other words, from the perspective of dynamic evolution, he distinguishes four development stages in the process of the institutionalization of the Triple Helix model. Then the main activities for each stage are identified and aligned with a variety of ideal institutional logics, drawing on the context of Western countries (Table 1). He argued that the contradictory institutional logics in a non-Western nation compared to the "ideal" in the West may cause barriers to implementing the Triple Helix model as well as opportunities for local innovation policies. The paper analysis indicated that developing an innovation system, the Triple Helix model, is not merely about how to manipulate the relations of academia, industry, and government for dynamic economic growth, but is also a matter of adjusting the institutional environment or institutional innovation.

3. Park and Leydesdorff (2010) first explained different mode indicators in their study, then, after applying the indicators, examined the possible results. They believe that significant progress has been achieved in understanding of this index as a benchmark. They studied two conditions of the indicators: (i) co-author networks of academic, industrial, and governmental authors as units of measurement and (ii) measuring synergies in the distributions of firms over geographical addresses, technological classes, and industrial-size classes for a number of nations. They concluded that these two analyses can quantify the difference between "globalizing" and "localizing." They argued that the large city can be expected to remain in transition between the local and global dimensions in small scale and produce the most synergies; these cities can reflect the global dynamics of a knowledge-based economy and become themselves a localized center of attraction for preferential attachments. 
Table 1 Institutional orders in the Triple Helix model

\begin{tabular}{|c|c|c|}
\hline Stages of development & Major Triple Helix activities & $\begin{array}{l}\text { Favorable institutional logics (market, } \\
\text { industry, firms, professions) }\end{array}$ \\
\hline Stage 1 & \multirow{2}{*}{$\begin{array}{l}\text { Realizing the importance of entering } \\
\text { a reciprocal relationship between } \\
\text { university, industry, and government }\end{array}$} & \multirow{2}{*}{$\begin{array}{l}\text { - Shared beliefs on knowledge as a } \\
\text { key to economic growth (logics of } \\
\text { economic growth in the field of } \\
\text { government and industry) }\end{array}$} \\
\hline Realization of the needs & & \\
\hline Stage 2 & \multirow[t]{3}{*}{ Taking the role of the other } & \multirow{2}{*}{$\begin{array}{l}\text { - Market-oriented organizational } \\
\text { cultures (logics of market at the state } \\
\text { level) }\end{array}$} \\
\hline \multirow[t]{2}{*}{$\begin{array}{l}\text { Intra-organizational } \\
\text { transformation }\end{array}$} & & \\
\hline & & $\begin{array}{l}\text { - Process-oriented management } \\
\text { culture in technology innovation } \\
\text { (logics of knowledge management in } \\
\text { the fields of industry and academia) }\end{array}$ \\
\hline Stage 3 & $\begin{array}{l}\text { Growing and innovating through } \\
\text { cooperation with others }\end{array}$ & \multirow{2}{*}{$\begin{array}{l}\text { - Effective protection for intellectual } \\
\text { property rights and market participants } \\
\text { (logics of intellectual property at the } \\
\text { field of industry) }\end{array}$} \\
\hline \multirow{2}{*}{$\begin{array}{l}\text { Interactions between } \\
\text { organizations in the } \\
\text { three sectors }\end{array}$} & \multirow[t]{2}{*}{ Generating hybrid organization } & \\
\hline & & $\begin{array}{l}\text { - Civil society (logics of civil society } \\
\text { at the state level) }\end{array}$ \\
\hline Stage 4 & $\begin{array}{l}\text { Feedback loops between policy-makers } \\
\text { and participants }\end{array}$ & $\begin{array}{l}\text { - Competitive market environment } \\
\text { (logics of competition in the field of } \\
\text { university) }\end{array}$ \\
\hline $\begin{array}{l}\text { Institutionalization of } \\
\text { the Triple Helix model }\end{array}$ & $\begin{array}{l}\text { Institutionalized norms of "entrepreneurial } \\
\text { university," "knowledge-based formation } \\
\text { and growth," and "innovation state" } \\
\text { (Etzkowitz 2008) }\end{array}$ & $\begin{array}{l}\text { - Democratic policymaking process } \\
\text { (logics of democracy in the field of } \\
\text { government) }\end{array}$ \\
\hline
\end{tabular}

Source: Cai (2013)

Articles that reviewed the Triple Helix model generally focused their attention on the shortcomings of this model to analyze knowledge-based innovation conditions of developing countries. Researchers considered the model function in countries with various institutional logics and stages of development to measure their movement toward knowledge-based economy and attempted to enhance the context sensitivity of the Triple Helix model. Also, these articles consider the Triple Helix model merely as a measure of synergies among academia, industry, and government which is indicative of realization of the knowledge-based economy.

A great deal of the studies in the field of Triple Helix model exist; this section only looked at a number of the most significant articles in the field of $\mathrm{TH}$ that were focusing on the underlying logics of this model and its consistency with the conditions of the developing countries.

However, the researchers of the current study investigate one of the shortcomings of the model that severely endangers its efficiency in identifying the economy of developing countries; also, they tried to provide a quick review of the evolution of Triple Helix model as well as clarifying its underlying logic.

\section{Discussion}

\section{Emergence of the Triple Helix model: the most important components}

Initial sparks of the Triple Helix model was based on the fact that knowledge-based innovation, as a sub-component of social mobility, was emerging and influencing economic system was introduced in 1993 by Henry Etzkowitz and the model was finalized in collaboration with Leydesdorff so that they held the first Triple Helix conference in 
Amsterdam. "Henry Etzkowitz and Leydesdorff offered three perspectives for the Triple Helix model, at first: evolutionary economy, sociology of science and technology, and sociology of higher education, as well as a policy analysis tool with political perspective" (Leydesdorff and Etzkowitz 2003).

During the past two decades, the model managed to gain a well-founded position in international scientific circles. Holding several conferences, international scientific forums, and forming study groups in accredited universities of the world are the signs of interest of scientific community in this model. Theoretically, this model has experienced content development during the past two decades which can be demonstrated in the following steps:

In the first place, "in a series of studies this potential synergy has been investigated in terms of inter-institutional coauthorship relations among authors with academic, industrial, and governmental institutions in the address bylines of the articles" (Leydesdorff and Strand 2012). For example, Leydesdorff (2003) used this method in his article. Using ISI database, he managed to demonstrate different patterns of integration at culturally different parts of the world. Leydesdorff concluded that industry and university cooperation in publishing scientific papers in European system was far less than the USA and countries in Southeast Asia. Many other researchers have used this method including Leydesdorff and Sun (2009), Park and Leydesdorff (2010) and Leydesdorff et al. (2006). "This data is readily available in bibliographic databases such as the Science Citation Index. However, the focus in these studies remains on the science system and not on innovation" (Leydesdorff and Strand 2012).

In the second step, "the Triple Helix model is generalized to a neo-evolutionary model by defining the three strands as functional dimensions of an innovation system: (i) economic wealth generation, (ii) socially organized knowledge production, and (iii) normative or regulative control. These functions can operate synergistically, without coupling, or against one another. The relationships can also change over time: synergy can be lost or gained with further development. Firms are the units of analysis; they can be considered from three analytically different perspectives: as organizations with different economies (small, medium, large); carriers of technological knowledge and knowhow; positioned in different administrative units such as regions, nations, and cities" (Leydesdorff and Strand 2012). Leydesdorff et al. (2006), for instance, considered Netherland's companies in three dimensions: organizational data were divided to 12 classes in term of number of personnel, the geographical location based on the provincial categorization, and technology dimension based on statistical classification of economic activities in Europe (NACE) were measured. Briefly, they concluded that (1) in implementing a knowledge-based economy, medium-tech production are much more important than high-tech production; high-tech services can ideally develop a knowledge-based system; however, in a limited scope. (2) Medium-tech production is the backbone of the country technology-economy structure. (3) Knowledge-focused services, not even with high technology level, leave relatively adverse effects on geographical aspects of the knowledge-based economy. It can be said that these services tend to separate knowledge base of their geographical dimensions. (4) Netherland's economy is developed with knowledge-based services; however, high-tech services remained low in terms of the number of companies. Strand et al. (2015), in a section of 
their research, divided synergies among the triple helix relations and analyzed these divisions in regions of Norway.

Directions of other changes of the model may be assessed by determining the type and number of the most influential and dynamic sub-dynamics of the society. "The Triple Helix encouraged researchers to reflect more than two dynamic factors (government and market)" (Leydesdorff 2012, p. 17). Extending this model was not limited to just three dynamic factors. Gradually, economists found that other social dynamic sub-dynamics can also be added to the model, with the provision that their inclusion increases the explanatory power of the model. Accordingly, the idea of developing quadruple, quintuple, and $\mathrm{N}$-tuple model was posed. "Leydesdorff and Etzkowitz (2003) argued that the helices indicate specialization and establishment of systems that emerged from urban community" (Leydesdorff 2012, p. 12). Therefore, any attempt to develop the triple helix model should be based on comprehensive and deep understanding of the institutional structure and functioning of social systems as well as analysis of dynamic sub-dynamics associated with knowledge-based changes in the considered society. "The Quadruple Helix type of innovation activity enables a larger variety of innovations than the Triple Helix model does. The Triple Helix type of innovation activity focuses on producing high-tech innovation based on the latest technology and research knowledge" (Report of Quadruple Helix Research For the CLIQ Project 2010, p. 15). In the studies conducted in this regard, depending on the structure of the studied communities, different dynamic sub-dynamics are considered as the fourth or fifth helices. In some of the researches, a strand called "culture-based and media-based" was added to the model as the fourth helix. The fourth helix refers to concepts like "media," "creative industries," "culture," "values," "life style," "art," and maybe "creative class" (a term, coined by Richard Florida 2004) (Carayannis and Campbell 2009, p. 7). Other researches (e.g., Carayannis and Campbell 2009) referred to the same concept as "civil society." Also, they added "environment" as the fifth helix to the model (Carayannis and Campbell 2010). According to them, "the Quintuple Helix model may be proposed as a framework for trans-disciplinary analysis of sustainable development and social ecology" (Carayannis and Campbell 2010, p. 61) (Fig. 1).

Other researchers, given the economic, social, and political circumstances of their studied country, tried to expand the triple helix model; for example, Leydesdorff and Sun 2009 and Park and Leydesdorff 2010 for Japan and South Korea identified the concept of "globalization" as the fourth helix to increase the explanatory power of the model. Considering all these interpretations, "one may wish to move beyond three relevant selection environments, but also a fourth (Carayannis and Campbell 2009) or fifth (Carayannis and Campbell 2010) dimension would require substantive specification, operationalization in terms of potentially relevant data, and sometimes the further development of relevant indicators. Without such a perspective, parsimony itself may be a methodologically well-advised strategy: so long as one is not able to operationalize and show development in the relatively simple case of three dimensions, one should be cautious in generalizing beyond the TH model to an N-tuple of helices" (Leydesdorff 2012, p. 17).

\section{Underlying institutional logic of the model}

No scientific model is able to understand and measure the knowledge-based economy unless it includes basic components of a knowledge-based institutional and organizational 


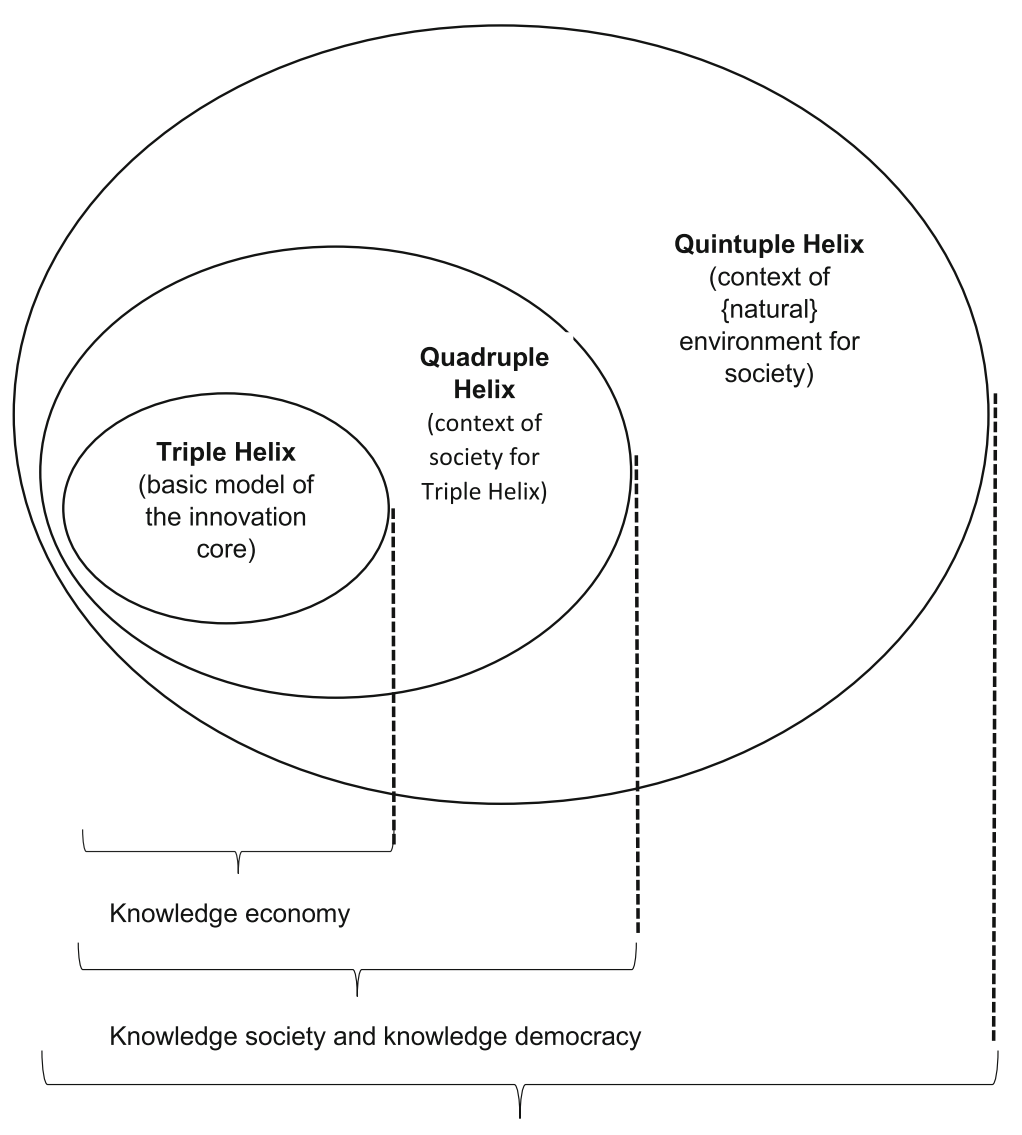

Socio-ecological transition

Fig. 1 Knowledge production and innovation in the context of the knowledge economy, knowledge society(knowledge democracy), and the natural enviroments od society. Modified frome carayannis and Campbell (2012, p.18), Etzkowitz and Leydesdorff (2000, p.112) and Danilda et al. (2009)

framework in its analysis, to make the bases of the model design. The Triple Helix model is also shaped on this basis by taking the characteristics of the knowledge-based economy as well as the importance of intellectual property rights of organizations into account. Knowledge-based nature of innovations has made the issue of intellectual property rights the guarantee for the achievement of this type of innovation, and the crucial key element of the knowledge-based economy. In the meantime, considering the concept of intellectual property as a critical issue is necessary for continuity and generation of the knowledge-based production system. Because, in the absence of reliable property rights system, suppliers of new ideas would not be able to sell their information to the market since the chance of reproducing and distributing such ideas has been made possible with little or no cost. But, only in return for obtaining monopoly, the owners of new ideas would reveal their thoughts. Therefore, only in a proper condition, i.e., with suitable legal protection, the information may become a commodity and logically, there would be the possibility of forming a market for it. There is a fundamental paradox in the determination of demand for information; its value for the purchaser is not known until he has the information, but then he has in effect acquired it without cost which arises only in the context of uncertainty. On the one hand, the purchaser is not certain of paying the price not until he knows about the information, and on the other hand, the owner is afraid of 
being cheated as soon as he reveals the information (Arrow 1959, pp. 9-10). Therefore, the importance of an effective intellectual property rights, as a requirement for continuity of the production process, especially knowledge-based production, seems to be more than any time before. Kamil Idris, stated in his book, which is published by World Intellectual Property Organization (WIPO), that "intellectual property could be called the Cinderella of the new economy. A drab but useful servant, consigned to the dusty and uneventful offices of corporate legal departments until the princes of globalization and technological innovation revealed her true" (Kamil Idris 2003, p. 24). In this regard, guarantee of property rights will undoubtedly play a key role in realization of a knowledge-based economy. Although the Triple Helix model has shifted its focus on this issue, it should be noted that ignoring other institutional components, that are not emphasized sufficiently but hidden in the model design implicitly, due to the models origin (in developed countries), can give rise to its ineffectiveness and weakness in explaining the conditions of other countries (in particular developing countries that lack institutional framework in order to development).

\section{Method}

As indicated in the Triple Helix model and its theoretical development, intertwined role of the three main agencies implementing knowledge-based economy, i.e., university, industry, and government, with some basic institutions such as property rights, on the one hand, and the need for institutional reforms to achieve knowledge-based economy (Momeni et al. 2012), on the other hand, is crucial to study the Triple Helix model or any other model to understand knowledge-based economy with theoretical framework with the greatest potential of organizational and institutional analysis.

Therefore, the current study implements the institutionalist economics as its theoretical framework. Its aim is to investigate the shortcomings and defects of the Triple Helix model with regards to analyzing the situation of the developing economies. A thorough explanation of such model is beyond the scope of the current study, thus, it focuses on the assumption that production based motivation structure is implicit in the economic context of all the countries.

Archival method of data collection is used in the current research and a descriptive-analytical method is used for data analysis.

\section{List of abbreviations}

1- Knowledge-based economy

During the 1970s and 1980s, development of tools and communication technologies founded the information revolution. Deep application and influence of information and extensive use of organized information, during the 1980s and 1990s, powered the rise of new economic system coined knowledge-based economy by OECD (Godin 2003, p. 6). According to their definition, knowledge-based economy is an economy that is directly based on production, distribution, and application of knowledge and information (OECD 1996, p. 7). In this economic system, knowledge plays a key role in creating efficiency. In recent years, the growth of knowledge-intensive sectors has gained significant attention as they become more crucial to competitiveness. The importance of 
knowledge-based activities to competitiveness is driven by a number of mutually reinforcing trends such as (Arrow 1959) the growth of information and communication technologies, (Abramowitz and David 1996) increased speed of scientific and technological advances and their diffusion, and (https:/www.britannica.com/biography/ James-Watt n.d.) the growing awareness of the value of specialized knowledge embedded in organizational processes (Z.Roldan 2015, p. 2). Synergies between the above-mentioned processes have led to fundamental changes in the economic and social structure of communities. "One of the major changes that emerged as a result of the knowledge revolution was substantial changes in the rules of the economic game. That is, if material and tangible elements (such as large factories, vast land, machinery and equipment, etc.) constituted key components of power until the third wave of the industrial revolution, under the new circumstances, human wisdom and network of relationships among them play the role of an engine for continuous development" (Momeni 2007, p. 5).

\section{2- Institution}

Institutions are guides to human interactions. Douglass North believes that institutions are the rules of the game in society, or in other words, are constraints imposed by human beings that shape their interactions with each other. As a result, institutions organize human incentives hidden in the interactions of whatever kinds, political, economic, or social (North 1990:20).

\section{3- Triple Helix model}

The Triple Helix model is an analytical model for explaining knowledge-based socioeconomic changes. Leydessdorff and Etzkowitz $(1995,2000)$ proposed the Triple Helix model of relations between and among university, industry, and government to explain the structure of development in a knowledge-based economy. In a knowledge-based economy, the community structure constantly changes by developments emanating from the science and technology. Accordingly, it is expected to change the community structure as well (Leydesdorff 2012, p. 2). By highlighting the role of three organizations, as main players in the development of knowledge-based development, exploring institutional ties between them, and providing a quantitative index for measurement of these relations, the model measures the degree of realization of the knowledge-based economy in a society. In other words, it enables the possibility of estimating the implications of developments in the knowledge-based society as well as the extent of their influence in order to achieve community development.

\section{Author contribution: the necessity of changing an economic system to achieve the knowledge-based economy}

One of the main elements of the knowledge-based economy, which is not explicitly mentioned in the Triple Helix model, is the "reward system reformation in favor of production-based activities" of a country's economic structure. As North says: wealth-maximizing of entrepreneurs occurs in the boundaries where the most lucrative 
options are offered. Whether it be the most promising alternative of piracy investment, a construction of an oil cartel, or a higher power computer chip processing, the existing limitations and changing incentives in borders of economic activity determine the opportunities (North 1981, p. 159). In other words, where the institutionalized framework rewards unproductive and rent activities, few ones swim against the tides. This problem will be more complicated when the ineffective institutionalized frameworks continue their life for a long period in underdeveloped countries. Thus, increasing returns of the institutional interconnected network will lead to the formation and growth of organizations that benefited from the resulting opportunities and increase the bargaining power of non-productive forces (North 1981, p. 157). Although the reward system has lost its relevance in developed countries since long time ago, and it actually supports productive activities at an acceptable level, it is still one of the biggest barriers of progress in developing countries. Disregarding the institutional rentier framework established in underdeveloped countries (in particular those depended on natural resources such as oil) faces the realization possibility of knowledge-based economy or any other productive activity with major challenges. Reward system determines the amount of possession, reward, and punishment of any economic activity, the feedback that is received for each activity can influence general direction of the countries' economic flow. Those activities that are sustained and reinforced by reward system of the institutionalized framework determine the tacit knowledge that is accumulated in the society and what kind of skills are more profitable to learn. Incentives that are part of the institutionalized framework, direct learning by doing, and development of tacit knowledge. Learning and developing tacit knowledge lead one in decision-making processes toward a military deformation which is different from (his) initial system (North 1990, p. 132). This issue becomes more important in the knowledge-based economy since, according to history, innovators that formed first and the second wave of industrial revolution and provided the knowledge-based revolution were not university graduates but individuals who used their personal experience to produce industrial inventions. Characters such as James Watt or Thomas Edison did not even succeed in finishing their primary education (Britannica), but their invention played a significant role in advancing the industrial revolution. Although the role of explicit knowledge in the structure of economy cannot be overlooked, the main point is efficiency and key role of tacit knowledge in the early formation stages of this system. In other words, through a reward and punishment mechanism, the reward system determines the kind of tacit knowledge that has to be accumulated in a society. Knowledge-based innovations are the engine of knowledge-based economy which continuously increase the performance and efficiency of the economic system and the accumulated tacit knowledge in the society determines the amount, type, and direction of these innovations (Fig. 2).

\section{Result}

Not applicable.

\section{Conclusion}

The Triple Helix model is known as one of the most successful models of determining and understanding the underlying relations of the knowledge-based economy. Understanding this model can provide us with deep and strategic understanding of the 


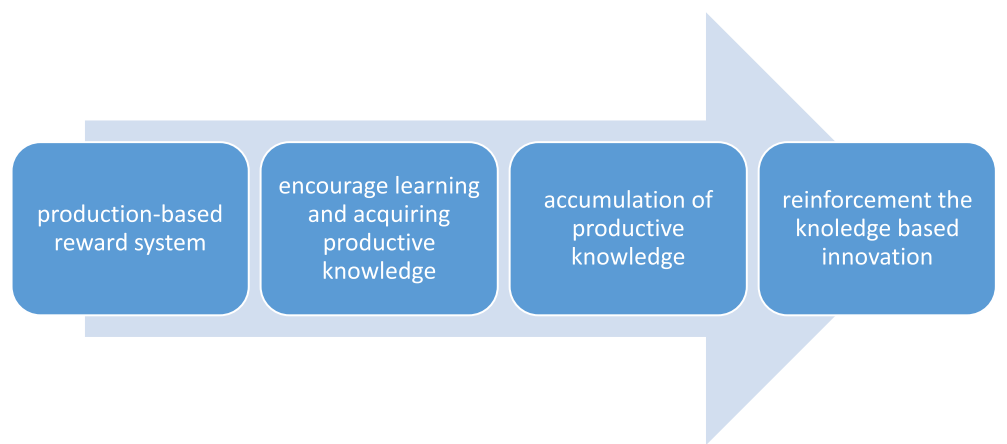

Fig. 2 Self-reinforcing mechanism of knowledge (innovation) based economy

structure of the knowledge-based economy, but there are still shortcomings and weaknesses in the model. They appear especially when the model is applied for analyzing different economic contexts. In this regard, one of the less considered points is the reward system of economy, without which the model efficiency in underdeveloped countries will be significantly reduced. It is a vital issue that the institutional framework of a country rewards which activities. Even if the intellectual property is guaranteed, a reward system that is inclined toward non-productive activities (such as brokerage, importing consumer goods, money trade, etc.) would never change the economic structure to the knowledge-based economy. Studying the Triple Helix model can result in valuable information for underdeveloped countries in order to move toward a knowledge-based economy but it is very essential to note that the knowledge-based economy is in essence the achievement of a production-oriented institutional framework. The knowledge-based economy constantly changes with knowledge-based innovations the main point is to give priority to reformation of the institutional framework so as to provide the conditions for formation of productive innovations. In case of establishing a knowledge-based economy, institutional framework and knowledge-based innovation will continually reinforce each other. Undoubtedly, the first step to establish a knowledge-based system is to form an institutional framework that supports productive activities. While presenting an overview of the Triple Helix model, the researchers in this study attempted to show the significance of reward system reformation as an essential component of production-oriented institutional framework.

In this study, we encountered some limitations, for example there is no precise indicator for measuring the concept of reward structure, especially in developing countries. In addition, many developing countries have a weak statistical organization and their data bank does not support the TH model. We suggest that future research can measure correlation between $\mathrm{TH}$ result and other indicators of knowledge economy in different countries.

Acknowledgements

Not applicable.

Funding

Not applicable. 
Authors' contributions

All authors read and approved the final manuscript.

\section{Competing interests}

The authors declare that they have no competing interests.

\section{Publisher's Note}

Springer Nature remains neutral with regard to jurisdictional claims in published maps and institutional affiliations.

\section{Author details}

${ }^{1}$ Faculty of Economics, Allameh Tabataba'i University of Tehran, Tehran, Iran. ' Master graduate of Allameh Tabataba'i University of Tehran, Tehran, Iran.

Received: 26 March 2018 Accepted: 20 November 2018

Published online: 11 January 2019

\section{References}

Abramowitz, M., \& David, P. A. (1996). Measuring performance of knowledge-based economy. In Employment and growth in the knowledge-based economy (pp. 35-60). Paris: OECD.

Arrow, K. J. (1959). Economic Welfare and the allocation of resources for invention. Californial: The Rand-Corporation.

Cai, Y. (2013). Enhancing context sensitivity of the triple Helix model: an institutional logics perspective. London: In The Triple Helix XI International Conference.

Carayannis, E. G., \& Campbell, D. F. J. (2010). Triple Helix, quadruple Helix and quintuple Helix and how do knowledge, innovation and the environment relate to each other? A proposed framework for a trans-disciplinary analysis of sustainable development and social ecology. International Journal of Social Ecology and Sustainable Development, 1(1), 41-69.

Carayannis, E. G., \& Campbell, D. F. J. (2009). 'Mode 3'and'Quadruple Helix': toward a 21st century fractal innovation ecosystem. International Journal of Technology Management, 46(3-4), 201-234.

Carter, A. P. (1996). Measuring the performance of a knowledge-based economy. In D. Foray \& B. A. Lundvall (Eds.), Employment and growth in the knowledge-based economy. Paris: OECD.

Danilda, I., Lindberg, M., \& Torstensson, B. M. (2009). Women resource centres: a quattro helix innovation system on the European agenda. In Högskolor och samhälle i samverkan: 01/06/2009-03/06/2009.

Etzkowitz, H., \& Leydesdorff, L. (1995). The triple Helix-university-industry-government relations: a laboratory for knowledgebased economic development. EASST Review, 14, 14-19.

Etzkowitz, H., \& Leydesdorff, L. (2000). The dynamics of innovation: from national systems and 'mode 2' to a triple helix of university-industry-government relations. Research Policy, 29, 109-123.

Florida, R. (2004). The rise of the creative class: and how it's transforming work, leisure, community, and everyday life. Cambridge: Basic Books

Godin, Benoit (2003), "The knowledge-based economy: conceptual framework or buzzword?" working paper No.24.

https://www.britannica.com/biography/James-Watt, Accessed 26 March 2018.

Idris, Kamil. (2003). Intellectual property: a power tool for economic growth (Vol. 888). WIPO.

Leydesdorff, L., \& Sun, Y. (2009). National and international dimensions of the triple Helix in Japan: university-industrygovernment versus international co-authorship relations. Journal of the American Society for Information Science and Technology, 60(4), 778-788.

Leydesdorff, L. (2003). The mutual information of university-industry-government relations: an indicator of the Triple Helix dynamics. Scientometrics, 58.2, 445-467.

Leydesdorff, L. (2012). The triple Helix, quadruple Helix and an N-tuple of helices: explanatory models for analyzing the knowledge-based economy? Journal of the Knowledge Economy, 3.1, 25-35.

Leydesdorff, L., Dolfsma, W., \& van der Panne, G. (2006). Measuring the knowledge base of an economy in terms of tripleHelix relations among 'Technology, organization, and territory,.' Research Policy, 35(2), 181-199.

Leydesdorff, L., \& Etzkowitz, H. (2003). Can 'the public'be considered as a fourth helix in university-industry-government relations? Report on the fourth triple Helix conference, 2002. Science and Public Policy, 30.1, 55-61.

Leydesdorff, L., \& Strand, Ø. (2012). Triple-Helix relations and potential synergies among technologies, industries, and regions in Norway. Procedia-Social and Behavioral Sciences, 52, 1-4.

Lundvall, B. A., \& Foray, D. (1996). The knowledge-based economy: from the economics of knowledge to the learning economy. Employment and Growth in the Knowledge-Based Economy, 14.

Meyer, M., Grant, K., Morlacchi, P., \& Weckowska, D. (2013). Triple Helix indicators as an emergent area of enquiry: a bibliometric perspective. Scientometrics, 99(1), 151-174.

Momeni, F. (2007). Iranian economy during the era of structural regulation (1st ed.). Tehran: Nagh-o-Negar publication.

Momeni, F., Najafi, S. M. B., \& Fathollahi, J. (2012). The necessity of economic structural transformation in developing countries toward a knowledge-based economy case study: Iran.

North, Douglass. C. (1990). Institutions, institutional change and economic performance. Cambridge university press.

North, Douglass. C. (1981). Structure and change in economic history. Norton.

OECD. (1996). The knowledge based economy. Paris, General Distribution: OECD/GD, 96, 102

Park, H. W., \& Leydesdorff, L. (2010). Longitudinal trends in networks of university-industry-government relations in South Korea: the role of programmatic incentives. Research Policy, 39.5, 640-649.

Report of Quadruple Helix Research For the CLIQ Project; 2010 (www.cliqproject.eu).

Roldan, M. D. G. Z. (2015). Sustaining "Lilliputs" in the global knowledge-based economy: prospects for micro, small, and medium-scale enterprises in the developing world. European Journal of Sustainable Development, 4.2, 269-274.

Strand, Øivind, Inga A. Ivanova, and Loet Leydesdorff. "Decomposing the Triple-Helix synergy into the regional innovation systems of Norway: firm data and patent networks." Available at SSRN 2567647 (2015). 